COMMENT. The monoamine neurotransmitter disorders are an expanding group of neurologic syndromes, usually diagnosed by measurement of neurotransmitter metabolites in the CSF. (Kurian MA, et al. Lancet Neurol 2011 Aug;10(8):721-33). Deficiency in dopamine is associated with movement disorder, deficient norepinephrine or epinephrine causes autonomic dysfunction, and serotonin deficiency results in sleep and psychiatric disorders. The members of the family described have symptoms of all neurotransmitter deficiencies but have no measurable deficiencies on CSF analyses. Symptoms result from impairment of synaptic transmission involving dopamineserotonin vesicular transport and caused by a gene mutation. Whereas L-dopa treatment exacerbated symptoms, a direct dopamine agonist caused a reversal of symptoms.

Dopamine agonists (pramipexole, ropinirole) have a direct dopaminergic effect on striatal neurons and, in the treatment of Parkinson disease, they may have a modulating effect on L-dopa and are associated with fewer dyskinetic motor complications. As a substitute for L-dopa, dopamine agonists require further study. Dosage appears all important, even small doses when first introduced may cause orthostatic hypotension and unpredictable sleepiness in adults. (Adams and Victor's Principles of Neurology, $9^{\text {th }}$ edition. Eds. Ropper AH, Samuels MA. New York, McGraw Hill Medical, 2009; 1041 42). Dopamine agonists have been used in the treatment of restless leg syndrome and are of benefit in the restoration of functional arousal, awareness, and communication in children following traumatic brain injury (Patrick PD et al. J Child Neurol 2006 Oct;21(10):879-85).

\title{
CHOREA ASSOCIATED WITH HHV-6 ENCEPHALITIS
}

Investigators at Brown University, Providence, RI and other centers in the US and Canada report a 14-month old child with multiple episodes of febrile status epilepticus, followed by chorea and developmental regression, caused by human herpes virus- 6 encephalitis. Chorea and seizures resolved following treatment with levetiracetam, IV immunoglobulin, and foscarnet, but developmental regression with loss of language skills persisted at 6 months follow-up. This is considered a novel manifestation of HHV-6 encephalitis. (Pulickal AS, Ramachandran S, Rizek P, Narula P, Scubert R. Chorea and developmental regression associated with human herpes virus-6 encephalitis. Pediatr Neurol 2013 Mar;48(3):249-51). (Response: Dr Pulickal, Division of Neonatology, Alpert Medical School of Brown University, Women \& Infants' Hospital, 101 Dudley Street, Providence, RI 02889. E-mail: apulickal@wihri.org).

COMMENT. HHV-6B is the cause of one third of all febrile convulsions in children under age 2 years in the United States (Hall CB, et al. N Engl J Med 1994 Aug 18;331(7):432-8), and a cause of mesial temporal lobe epilepsy after febrile status epilepticus (Theodore WH, Epstein L, Gaillard WD, et al. HHV-6B: a possible role in epilepsy? Epilepsia 2008 Nov;49(11):1828-37). Other disorders attributed to HHV-6 infection include meningoencephalitis, encephalopathy, demyelinating diseases, ataxia, opsoclonus-myoclonus, and cranial neuropathies. In addition to symptoms of involvement of the cerebral cortex, brain stem, cerebellum, spinal cord, hippocampus, and mesial temporal lobe, HHV-6 infection may also present with symptoms of basal ganglia virus involvement, either direct or autoimmune. 